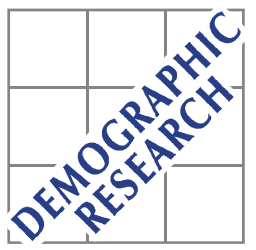

Demographic Research a free, expedited, online journal of peer-reviewed research and commentary in the population sciences published by the Max Planck Institute for Demographic Research Konrad-Zuse Str. 1, D-18057 Rostock · GERMANY www.demographic-research.org

DEMOGRAPHIC RESEARCH

VOLUME 14, ARTICLE 13, PAGES 267-294

PUBLISHED 29 MARCH 2006

http://www.demographic-research.org/Volumes/Vol14/13/

DOI: 10.4054/DemRes.2006.14.13

Research Article

Survival differences among the oldest old in

Sardinia: who, what, where, and why?

Graziella Caselli

Rosa Maria Lipsi

(C) 2006 Max-Planck-Gesellschaft. 


\section{Table of Contents}

1 Introduction $\quad 268$

2 Data and methods $\quad 269$

2.1 Data 269

$\begin{array}{lll}2.2 & \text { Methods } & 270\end{array}$

3 Mortality and survival in Sardinian provinces 271

$\begin{array}{lll}3.1 & \text { Sardinia within the Italian context } & 271\end{array}$

$\begin{array}{ll}3.2 & \text { The provinces compared } \\ 3.3 & 273\end{array}$

3.3 Mortality by cause and survival among over 80-year olds 276

$4 \quad$ Inter-municipality differences in mortality 282

4.1 Geography of mortality: total and by causes of death 282

$\begin{array}{lll}5 & \text { Some answers } & 287\end{array}$

6 Acknowledgements $\quad 289$

References 290 


\title{
Survival differences among the oldest old in Sardinia: who, what, where, and why? ${ }^{1}$
}

\author{
Graziella Caselli ${ }^{2}$ \\ Rosa Maria Lipsi ${ }^{3}$
}

\begin{abstract}
A study of centenarians in Sardinia detected the existence of an area where the number of centenarians is higher than elsewhere, in particularly for men. There is a widespread opinion that the existence of a greater or a lesser number of centenarians largely depends on mortality features between 80 and 100 years. This study aims to cast light on our knowledge of elderly mortality differentials, total and by cause of death, in Sardinia, and attempts to verify this hypothesis. To do so, an analysis is conducted of age and sex mortality trends over time at province and municipality level. Results fully confirm the underlying hypothesis.
\end{abstract}

\footnotetext{
${ }^{1}$ The results presented here are part of the research project "Demography of Sardinian mortality", directed by James Vaupel and funded by the Max Planck Institute for Demographic Research, Rostock.

2 Department of Demography, University of Rome "La Sapienza"

3 Department of Demography, University of Rome "La Sapienza"
} 


\section{Introduction}

The exceptional proportion of centenarians on the Italian island of Sardinia $(1,650,000$ habitants), and their more balanced sex ratio, has led to considerable interest among demographers, geneticists, gerontologists and clinicians specialising in genetic mapping (DNA) (Caselli et al. 2003).

Interest in understanding the underlying processes of living to advanced ages is widespread: in Sardinia (as elsewhere) the main focus has been on investigating the influence of both biological charateristics and life histories on longevity. An intriguing aspect of Sardinian centenarians is that their gender differences do not follow tha same patterns observed in North and Centre Italy nor that observed in other low mortality countries. The female/male ratio among centenarians in Sardinia is 2.7:1 in comparison to 5:1 for Italy, in some Northern regions of Italy the sex ratio can be as high as 7:1. Female/male ratios are usually 5-6:1 in other developed countries (Robine and Caselli 2005). The underlying reasons for these differences have been studied together with other researchers as part of the recent $\mathrm{AKEA} 2^{4}$ project. This is part of a larger international research project whose aim is to study the bio-demographic features of Sardinian centenarians and their exceptional longevity (see note 2).

Previous research shows a higher concentration of centenarians in an inland area of the island, more or less coinciding with the province of Nuoro (Poulain et al. 2004). There is widespread consensus that the presence of a greater or lesser number of centenarians is largely due to mortality differentials at age 80 to 100 (Vaupel and Jeune 1995, Thatcher 2001). Lower mortality among this age group implies that more people should live until they are aged 100 or over. Swiss forecasts (Robine unpublished) confirm that $40 \%$ of the increase in the number of centenarians between 1970 and 2000 can be traced to decline in mortality among 80- to 100-year olds. Caselli and Rasulo (2005) have shown that in Sardinia, compared with Italy, 60 per cent of the higher proportion of male centenarians born between 1880 and 1902 is due to lower mortality among 80 to 99 -year old Sardinian men.

While cohort behaviour is the key to understanding demographic processes, what clearly emerges from centenarian mortality studies is the crucial role played by period analysis of both geographic and gender mortality differences. Both these aspects are pivotal to this study where particular focus will be given to mortality trends and features among individuals aged 80 and over. A primary aim will be to identify geographic areas that are homogenous with regard to low mortality and investigate whether these areas also have a high proportion of centenarians. Another aim is to study the causes

${ }^{4}$ AKEA2 is the name of the project "Demographic Analysis of Longevity. A Survey on Sardinian Centenarians" directed by James Vaupel, Max Planck Institute (funded by NIA, US, subcontract with Duke University n.03-SC-NIH-1027). 
underpinning observed geographic mortality differences, with a particular focus on morbidity leading to death that facilitates identifying the risk factors involved. The study of the cause of death favours a shift from a merely descriptive to a more explanatory analysis of mortality differences.

In summary, in the first section of the study, after describing the data and methods used, elderly male and female survival trends during the last three decades of the XX century, are analysed and a comparison is made between Italy and Sardinia and provinces and regions. Our focus is on the analysis of mortality differentials - all-cause and cause-specific - between Sardinia and Italy; namely mortality differences between a) Sardinian provinces and municipalities and b) men and women, the goal being to identify homogenous zones according to mortality levels and patterns.

\section{Data and methods}

\subsection{Data}

Mortality and population data used are from ISTAT and Emilia-Romagna Regional Authority databases ${ }^{5}$.

For the population of Italy and the regions the census population and the population estimates for every calendar year from 1952 to 2001 have been used (Golini et al. 1983, Capocaccia et al. 1990, ISTAT 2000a). For Sardinian provinces and municipalities reference is to the census population for the years 1971, 1981, 1991 and 2001, and that reconstructed on January 1 for every year between 1971 and 2001 (Capocaccia et al. 1990, ISTAT 1974198519951996 2000a). For the municipalities population data by age is available for single years of age starting in 1981 to 2002 (see footnote 5 and ISTAT 2004a).

Mortality data are provided by ISTAT, and are available at the municipal, provincial and regional level, and by individual age for the years 1969 to $2000^{6}$. For Italy and its regions (including Sardinia) ISTAT life tables are available for the years close to the census, starting from 1951, and for more recent calendar years starting from 1997 (ISTAT 1976 1987, www.istat.it). Life tables at the provincial level have been constructed close to the 1971, 1981, 1991 censuses (Lipsi and Caselli 2002), but these life tables only go up to age 85+. ISTAT provincial life tables for all ages only date from 1995 (for 1995 see ISTAT 2000b, for 2000 see www.istat.it).

\footnotetext{
${ }^{5}$ Atlante Italiano di Mortalità 1981-1994 (1998).

${ }^{6} \mathrm{We}$ are grateful to ISTAT and to Dr. Silvia Bruzzone in particular for her assistance and kindness.
} 
As part of this study provincial life tables for Sardinia were constructed for ages up to 99 and for the years 1975-77, 1978-80, 1981-83, 1984-86, 1987-89, 1990-92, 199395, 1996-97 and 1998-20007.

Mortality probabilities by cause of death for the periods 1975-1977, 1996-1997, and 1998-2000 were also constructed, with comparisons between Sardinian and Italy, and Sardinia and each of the four provinces. Male and female mortality probabilities were calculated by 5 -year age group, from 80 to 99 years. Causes of death considered in this study were classified and coded according to the International Classification of Diseases, Revision IX (ISTAT, 1984). These included: Cardiovascular diseases (390459); Ischaemic heart diseases (410-414); Cerebrovascular diseases (430-438); Other cardiovascular diseases (390-398; 401-405; 440-459); Cancers (140-239); Other causes (001-139; 240-389; 460-466; 470-999).

Standardized mortality ratios (SMR) for 1981-1989 and 1990-1994 were calculated for each of the $363^{8}$ municipalities. The ratios refer to those aged 80 and over and by causes of death referred to above.

\subsection{Methods}

The main methods described are those regarding the construction of provincial life tables and mortality and survival indicators as well as spatial analysis methods to define geographically homogeneous areas with regard to oldest old mortality.

To obtain synthetic mortality indicators by provinces, life tables were constructed for the three year periods indicated above and mortality rates were calculated for ages up to age 79 and estimated for ages above age 80. For this estimation a modified logistic function was applied as proposed by Kannisto (Kannisto et al.1994) and referred to as KVLF (Kannisto variant logistic function). This analytical method was used because the mortality trajectory slows down rather than increases exponentially toward the end of life (Kannisto 1994, Thatcher et al. 1998). Once all the mortality rates were calculated mortality probabilities for the life tables were calculated using the method proposed by Caselli and Egidi (for more details of this method please see Caselli and Egidi 1980).

Standardized mortality ratios (SMR) were calculated by municipalities (for allcause and specific cause mortality) for ages 80 and over according to procedures applied in epidemiology by Kahn and Sempos (1989). These ratios were constructed as

${ }^{7}$ Life tables were constructed as part of the Sardinian centenarian project funded by the Max Planck Institute for Demographic Research, Rostock. Elisabetta Barbi and Cecilia Tomassini have participated to this project (Caselli et al. 2002).

${ }^{8}$ According to the 2001 census there are 377 municipalities in Sardinia. The 363 selected here are geographically similar compared with the starting date of the municipal analysis (1981). 
part of the project mentioned in footnote (1). The SMRs express the relationship between observed deaths in the Sardinian municipalities and expected deaths, or rather deaths that would have occurred if mortality was the same as in the reference population. The standard population used is that for Sardinia at the 1981 census. However, for small municipalities the expected deaths, particularly when dealing with specific-cause mortality, is often less than one and therefore when the SMR is calculated values can be very high. This may cause great variability among municipalities of the same size and also a high random error. Hence, detailed geographic maps of standard SMR values for numerous small municipalities tend to be extremely "spotted" and hard to read.

To overcome this drawback the Kernel density estimator (Biggeri et al. 1993, Silverman 1986) is used to construct geographic maps of density estimators of standard ratios. To obtain a series of such indicators a method of estimation for the density function on the frequency of death is applied, taking into account the population density of the various municipalities. Kernel density estimators are the smoothed SMRs obtained as the spatial moving average for a number of municipalities adjacent to a given municipality. Spatial moving averages are weighted and the parameter used is the inverse of the distance between each municipality and the municipality of reference. The subsequent maps obtained using these new indicators show groups of municipalities that share homogeneous mortality patterns and are easier to read than those that use standard SMRs (Camnasio et al. 1996).

\section{Mortality and survival in Sardinian provinces}

The best synthetic measure of mortality over time and space is undoubtedly life expectancy at different ages. As each geographic analysis requires a point of reference for comparison, for Sardinia, Italy as well as North-West, North-East, Centre and South Italy were selected. The South includes Sardinia. For the provinces and municipalities the region itself was used.

\subsection{Sardinia within the Italian context}

Taking life expectancy at birth at the beginning of the XXI century an Italian man could expect to live an average of 76.5 years, the same more or less as his counterpart in Sardinia and in the rest of the South. For women, the national life expectancy at birth is 82.5 years in comparison with 83 in Sardinia, 81.7 in the South and 83.2 in the North- 
East of Italy. Thus in the North-East a newly born infant in 2000 may expect to live 1.5 years longer than his peer in the South.

This ranking changes for life expectancy at 80 years. For men, elderly Sardinian men have the highest life expectancy, 7.6 years compared with 7.3 for Italy and 7.2 in the North-West. For women, similar to the situation at birth, their life expectancy is higher in the North-East and lower in the South (9.6 compared with 8.7 years). Sardinian men aged 100 maintain their ranking, with a life expectancy of 1.9 years compared with 1.8 in the North-West. Women aged 100 maintain the same positions as at age 80, with a life expectancy of 2.1 years in the North-East, 1.9 in the South and 2 in Sardinia (Table 1).

Table 1: Life expectancy for men and women, at different ages in Italy, in 4 geographic regions and in Sardinia, in 2000 (ISTAT 2004a)

\begin{tabular}{|c|c|c|c|c|c|c|c|c|c|c|c|c|}
\hline Age & Italy & & North V & & North & & Centre & & South & & Sardini & \\
\hline & M & W & M & W & M & W & M & W & M & W & M & W \\
\hline 0 & 76.5 & 82.5 & 76.3 & 82.7 & 76.8 & 83.2 & 77.1 & 82.8 & 76.3 & 81.7 & 76.3 & 83.0 \\
\hline 80 & $7.3^{*}$ & $9.2^{*}$ & 7.2 & 9.2 & 7.5 & 9.6 & 7.4 & 9.2 & 7.2 & 8.7 & $7.6^{*}$ & $9.3^{\star}$ \\
\hline 100 & 1.8 & 2.0 & 1.8 & 2.0 & 1.9 & 2.1 & 1.8 & 2.0 & 1.8 & 1.9 & 1.9 & 2.0 \\
\hline
\end{tabular}

* Our estimations for the period 1998-2000 are: for Italy 7.5 for men and 10.1 for women; for Sardinia are respectively 7.8 and 9.8 .

It should be noted that the ISTAT methods used to construct life tables tend to overestimate mortality at the upper limits of life, thus underestimating average survival'. By applying Kannisto's method to correct these overestimate (Kannisto et al. 1994) and regrouping the data (1998-2000), in Sardinia, for example, average life expectancy at 80 years for men is 7.8 years (rather than 7.6) and 9.8 years for women (rather than 9.3). At age 100 this is respectively 2.4 and 2.5 years (rather than 1.9 and $2.0)^{10}$. Using Kannisto's method does not have an impact on previously observed geographic differences (i.e. the relative ranking across the regions remain about the same) although life expectancies are slightly different than those produced by ISTAT as shown in Table 1.

Focusing on Sardinia (as well as the rest of the South) the first interesting finding regards the life expectancy of centenarians. Figures for men and women are similar,

\footnotetext{
${ }^{9}$ Until 1998, Istat estimates over 90-year old mortality probabilities using an exponential function. The probabilities reported here, using Kannisto's method, are based on a logistic function, with a deceleration of mortality rate after 80 years.

${ }^{10}$ These data may be obtained from graziella.caselli@uniroma1.it.
} 
implying that mortality after age 100 is on average similar for both sexes. In the period 1975-1977 Sardinian longevity is more similar for men and women also at age 80 .

A number of substantial gender differences emerge in inland Sardinia. A twentyyear analysis of each individual province shows these trends.

\subsection{The provinces compared}

Table 2 clearly shows that inland on the island survival differences by province exist. Recent data show that the most disadvantaged life expectancies by birth are infants born in Nuoro, with a life expectancy of 75.4 years in 1998-2000, compared with a regional average of 76.3 years (Table 2) and 76.7 in the province of Oristano. For girls, on the other hand, life expectancy is highest in Oristano and Cagliari, with an 83.6 and 83-year life expectancy at birth respectively, the same as for Sardinia as a whole.

Table 2: Life expectancy in Sardinian provinces at age 0,80 and 100 years, for men and women; years 1975-1977, 1996-1997 and 1998-2000 (mortality after age 80 estimated by the KVLF method)

\begin{tabular}{|c|c|c|c|c|c|c|c|c|c|}
\hline \multirow[t]{2}{*}{ Provinces } & \multicolumn{3}{|c|}{$1975-1977$} & \multicolumn{3}{|c|}{ 1996-1997 } & \multicolumn{3}{|c|}{$1998-2000$} \\
\hline & $e_{0}$ & $e_{80}$ & $e_{100}$ & $\mathrm{e}_{0}$ & $e_{80}$ & $e_{100}$ & $e_{0}^{(1)}$ & $e_{80}$ & $e_{100}$ \\
\hline \multicolumn{10}{|l|}{ Men } \\
\hline CAGLIARI & 70.9 & 6.3 & 2.0 & 75.2 & 7.4 & 2.2 & 76.5 & 7.6 & 2.3 \\
\hline NUORO & 72.0 & 7.3 & 2.4 & 74.8 & 8.4 & 2.8 & 75.4 & 7.9 & 2.5 \\
\hline ORISTANO & 69.5 & 6.1 & 1.9 & 75.5 & 7.7 & 2.3 & 76.7 & 7.8 & 2.4 \\
\hline SASSARI & 70.9 & 6.9 & 2.3 & 75.7 & 8.6 & 2.9 & 76.4 & 8.1 & 2.6 \\
\hline Sardinia & 71.0 & 6.7 & 2.2 & .. & .. & .. & 76.3 & 7.8 & 2.4 \\
\hline \multicolumn{10}{|l|}{ Women } \\
\hline CAGLIARI & 76.5 & 6.5 & 1.6 & 82.3 & 9.5 & 2.4 & 83.0 & 10.1 & 2.5 \\
\hline NUORO & 77.1 & 6.9 & 1.6 & 81.4 & 9.2 & 2.3 & 82.9 & 10.0 & 2.6 \\
\hline ORISTANO & 75.2 & 6.0 & 1.5 & 81.7 & 9.5 & 2.3 & 83.6 & 10.4 & 2.5 \\
\hline SASSARI & 76.5 & 6.6 & 1.7 & 82.0 & 9.0 & 2.2 & 82.6 & 8.8 & 2.1 \\
\hline Sardinia & 76.5 & 6.6 & 1.7 & .. & .. & .. & 83.0 & 9.8 & 2.5 \\
\hline \multicolumn{10}{|c|}{ Differences: Women-Men } \\
\hline CAGLIARI & 5.6 & 0.2 & -0.4 & 7.1 & 2.1 & 0.2 & 6.5 & 2.5 & 0.2 \\
\hline NUORO & 5.1 & -0.4 & -0.8 & 6.6 & 0.8 & -0.5 & 7.5 & 2.1 & 0.1 \\
\hline ORISTANO & 5.7 & -0.1 & -0.4 & 6.2 & 1.8 & 0 & 6.9 & 2.6 & 0.1 \\
\hline SASSARI & 5.6 & -0.3 & -0.6 & 6.3 & 0.4 & -0.7 & 6.2 & 0.7 & -0.5 \\
\hline Sardinia & 5.5 & -0.1 & -0.5 & .. & .. & .. & 6.7 & 2.0 & 0.1 \\
\hline
\end{tabular}

Source: our elaboration of ISTAT data.

(1). Life expectancy data at birth is for 2000 , ISTAT provincial tables.

.. Data not available 
Male survival ranking has changed over time. For the years 1975-77, a baby boy at birth had the highest life expectancy in the province of Nuoro. Recently, the province at the top of the scale regarding male and female life expectancy at birth is Oristano.

In Sardinia, mortality differences by sex are such that the Sardinian provinces represent an isolated case regarding elderly mortality in Italy (Lipsi and Caselli 2002). Table 2 shows that at the end of the 1970's male and female life expectancies were fairly similar at age 80, however at age 100 male survival was decidedly higher. It is only more recently that women aged 80 live longer on average than men, while at age 100 (as could also be seen from the ISTAT data in table 1), survival is largely similar for both men and women.

Focusing on differences by provinces and by gender, and considering our estimation in 1998-2000 at age 80, Cagliari and Oristano had the highest female life expectancy (10.1 and 10.4 years) and the lowest for men (7.6 years in Cagliari and 7.8 years in Oristano). In Nuoro and Sassari, however, male life expectancy was highest at this age (7.9 years and 8.1 years respectively) and, for Sassari, the lowest for women (8.8 years). Life expectancy at age 100 for men in Sassari is again higher than for women: in 1975-1977 men at age 100 could hope for a further 2.3 years on average compared to 1.7 years for women. Currently this is 2.6 for men and 2.1 for women. In Nuoro corresponding figures are respectively 2.4 and 1.6 in the first period and 2.5 and 2.6 in the second one (Table 2). Although they were slightly privileged or even disadvantaged, as was the case with Sassari, women have recently gained more than men whose situation, in some instances, even worsened during the ' 90 's.

It is quite rare, apart from at extreme ages, to observe higher life expectancy for men compared to women. The situation for Sassari, that already existed in other provinces on the island at age 80 (Table 2), had already emerged for the province of Nuoro in a previous study of mortality trends in 94 Italian provinces for the years 197173, 1981-83 and 1991-93 (Lipsi and Caselli 2002).

Recent trends in sex differences in mortality among the provinces is an important feature of the study of mortality in Sardinia. Figure 1 compares male and female mortality probabilities in the 1970's and at the end of the 1990s. Figure 1 highlights how the cross-over between the male and female mortality curve shifts towards the upper ages over time for all the provinces. Of note are the four provinces where the cross-over occurred around age 80 in the 1970's, while after age 90 in 1998-2000 and only for Sassari. Why were 80-year old men at an advantage over women thirty years ago? Why recently this advantage disappeared? There is no doubting the fact that the 80-year olds in the period 1975-1977 are today's centenarians and that their life expectancy is similar to that of women. Clearly it is not possible to explain this phenomenon only through an analysis of life tables. Similarly it is not possible to understand provincial level sex differences in mortality without analysing individual 
and community risk factors. In demography, to furnish some sort of explanation, at least the causes of death that produce these differences are required.

Figure 1: Comparison of probabilities of death from age 50 to 99 years for men and women at 1975-1977 (left) and 1998-2000 (right), in four Sardinian provinces
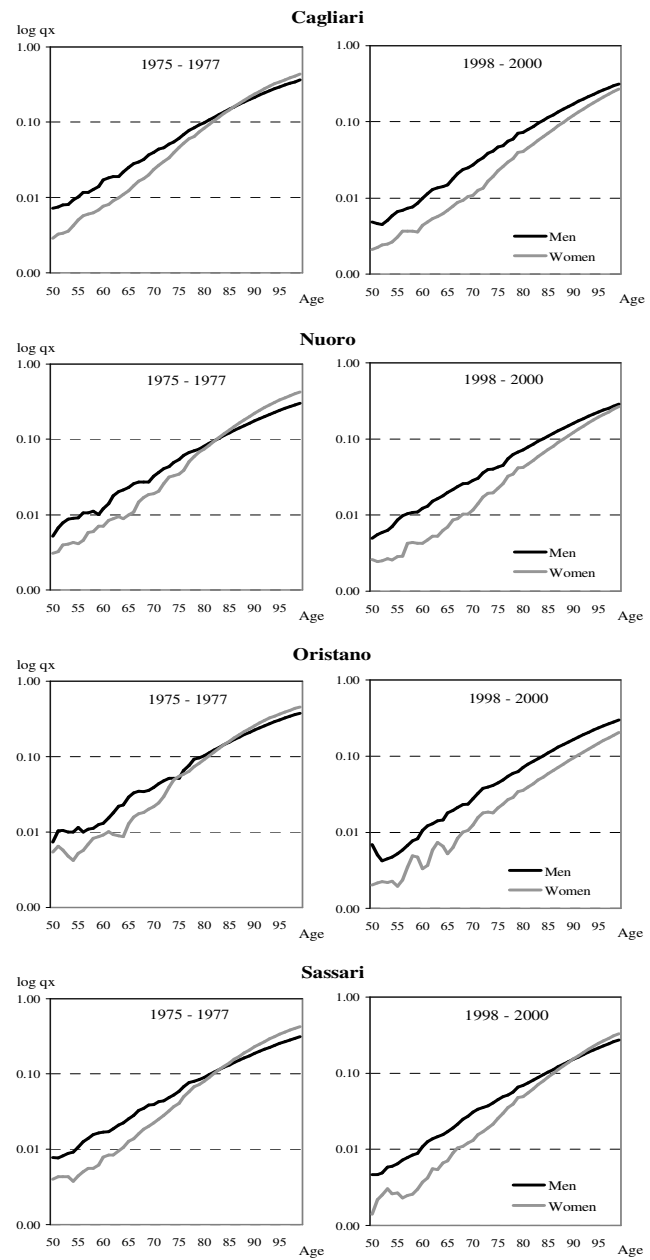


\subsection{Mortality by cause and survival among over 80-year olds}

Using Pollard's decomposition method (1986) it is possible to identify to what extent mortality for each specific-cause of death influences differences in life expectancy at age 80 between a) Sardinia and Italy, b) the regions and each province and c) the sexes in each geographic zone. Positive gains in life expectancy (expressed as fractions of years of life) shown in Figure 2 reflect the positive contribution of that mortality by specific cause to the Sardinian-Italian difference in life expectancy by different age gropus; thus, mortality from that specific cause of death is lower in Sardinia than in Italy. Conversely, negative contributions to life expectancy reflect lower mortality for that specific cause of death in Italy when compared to Sardinia. Most of the 0.3 average male life years to the advantage of 80 -year old Sardinians is due to lower mortality at all ages (the plus being higher than the minus contribution) for cardiovascular diseases (ischaemic, and other cardiovascular diseases) and cancers (aged 80-89 groups). However, taking "other causes" Sardinians are at a disadvantage, with respiratory diseases (bronchitis, pneumonia and influenza: data available but not highlighted in the figure) playing a leading role. Sardinian women, whose survival is slightly lower than that for women on the mainland, like men, are at an advantage regarding mortality from cardiovascular diseases. A similar result emerged during a previous study for both genders (Caselli et al. 2005) regarding mortality at age 80-99 years for cohorts born in 1891-1902. Of note is the fact that, even when referring to period data, results show that elderly mortality among Sardinians from cardiovascular causes is lower than for Italians. This is crucial for their greater longevity.

The same methodology is applied to study survival differences between the provinces and Sardinia. Focus is given to the main results for the provinces of Nuoro and Cagliari that, - excluding Oristano - , respectively, for men have had for a long period the highest and lowest life expectancy, and the province of Sassari that has the lowest female life expectancy at age 80. Figure 3 reveals that the recent advantage for men aged 80 in Nuoro compared with Sardinia is due to lower mortality for cerebrovascular diseases and, at least for ages 80-84 years, cancers. Their advantage in the 1970's could also be traced to lower mortality for other cardiovascular diseases and ischaemic hearth diseases, that played a negative role in 1998-2000. This is generated by the fact that men from Nuoro, with the highest life expectancy in 1975-1977, made fewer gains than elsewhere in the period considered ( 0.6 years compared with the Sardinian average of 1.1 years). A smaller drop in mortality for both these causes may be blamed (Figure 3, Table 2). This also applies to women (Figure 4) who, unlike men, experienced a similar increase in life expectancy to that of the regional average (3.1 years compared with 3.2) (Table 2). It could be said that the "cardiovascular revolution" did not affect the Sardinian provinces uniformly and Nuoro was the province that least exploited the benefits of modern treatments for these diseases and prevention services 
available throughout the region. Eighty-year olds from this province risk losing most of the advantage previous generations enjoyed and this could have an impact on the future size of the centenarian population.

Figure 2: Contributions of mortality by cause of death to differences in life expectancy at age 80 between Sardinia and Italy, for men and women, in 1998-2000 (Life expectancy: Sardinia 7.8 years and Italy 7.5 years for men and, respectively, 9.8 and 10.1 years for women
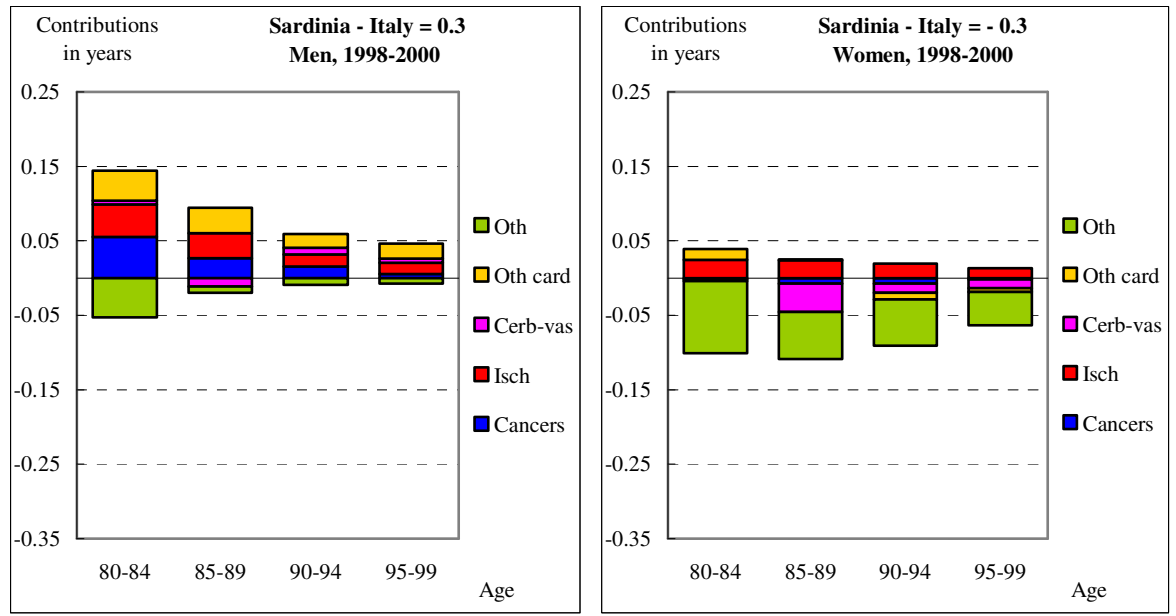

The province of Cagliari, with the lowest life expectancy at age 80 for men, is at a disadvantage due to higher mortality for cerebrovascular diseases, "other diseases" and cancers (negative contribution) (Figure 3).

Women from the province of Sassari compared with those from Sardinia, in the last period, are disadvantaged in terms of all-cause mortality. Mortality from cardiovascular diseases is much higher that the average and this is the group most disadvantaged in terms of this cause of death in Sardinia.

At this point, given the existence of provincial level sex differences in life expectancy it is of interest to examine the underlying causes of death. Figure 5 shows the increased gap in 1998-2000 to the advantage of women in all the provinces, although less so in Sassari. Positive contributions confirm that the increased gender gap 
in favour of women is largely due to lower female mortality from all cardiovascular diseases and cancer.

While the gain in women's life expectancy compared with men is due to lower mortality from cancer (especially in Oristano) and ischaemic heart diseases, equally important is the role played by mortality from "other causes".

At a time when mortality is dropping these results demonstrate women's greater ability to implement preventive measures and exploit modern treatments now available. If these differences in attitudes to health persist and increasingly continue to affect sex differences in mortality it may be that when the current generation of 80-year olds become centenarians Sardinian men may lose their current advantage as today's cohorts of centenarians pass away. 
Figure 3: Contributions of the mortality by causes of death to the differences in life expectancy at age 80 years between provinces and Sardinia, for men, in 1975-1977 and 1998-2000 (for life expectancy see Table 2)
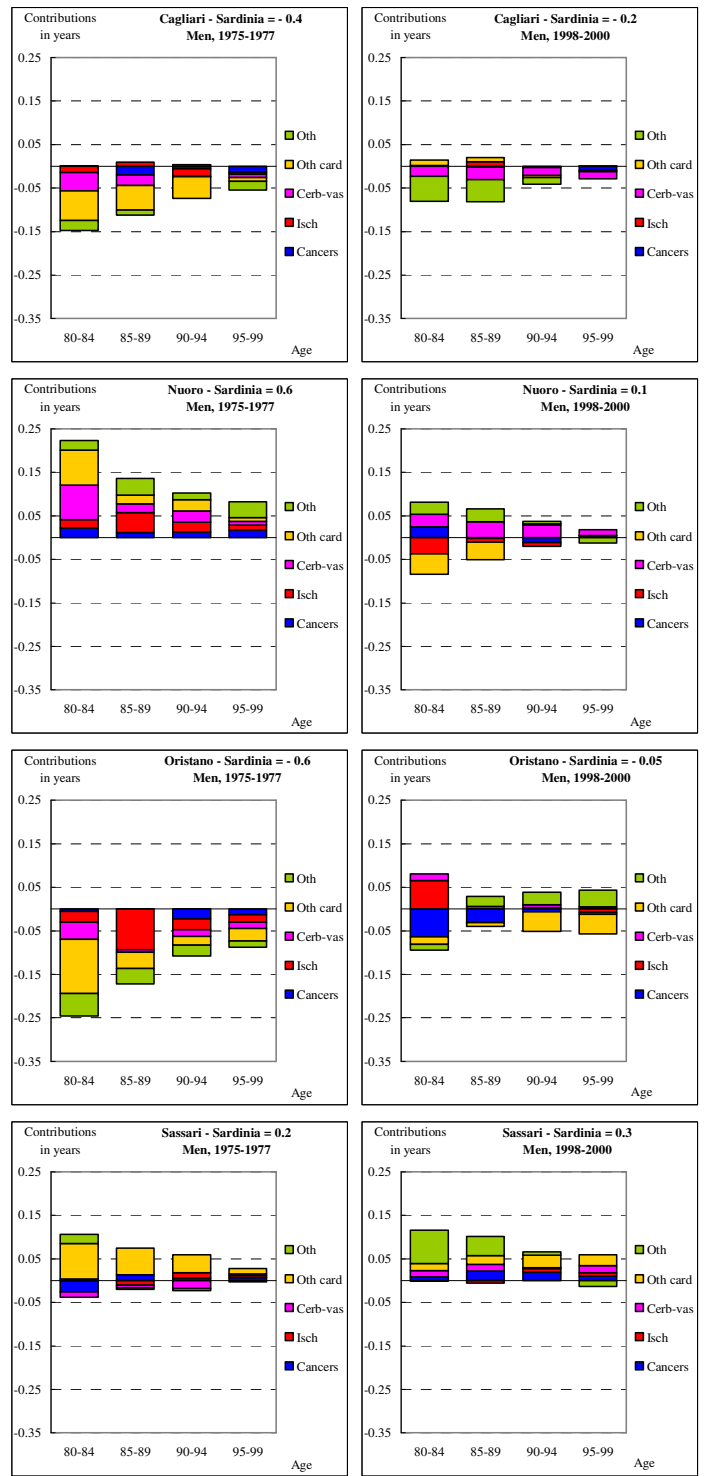
Caselli \& Lipsi: Survival differences among the oldest old in Sardinia

Figure 4: Contributions of the mortality by causes of death to the differences in life expectancy at age 80 years between provinces and Sardinia, for women, in 1975-1977 and 1998-2000 (for life expectancy see Table 2)
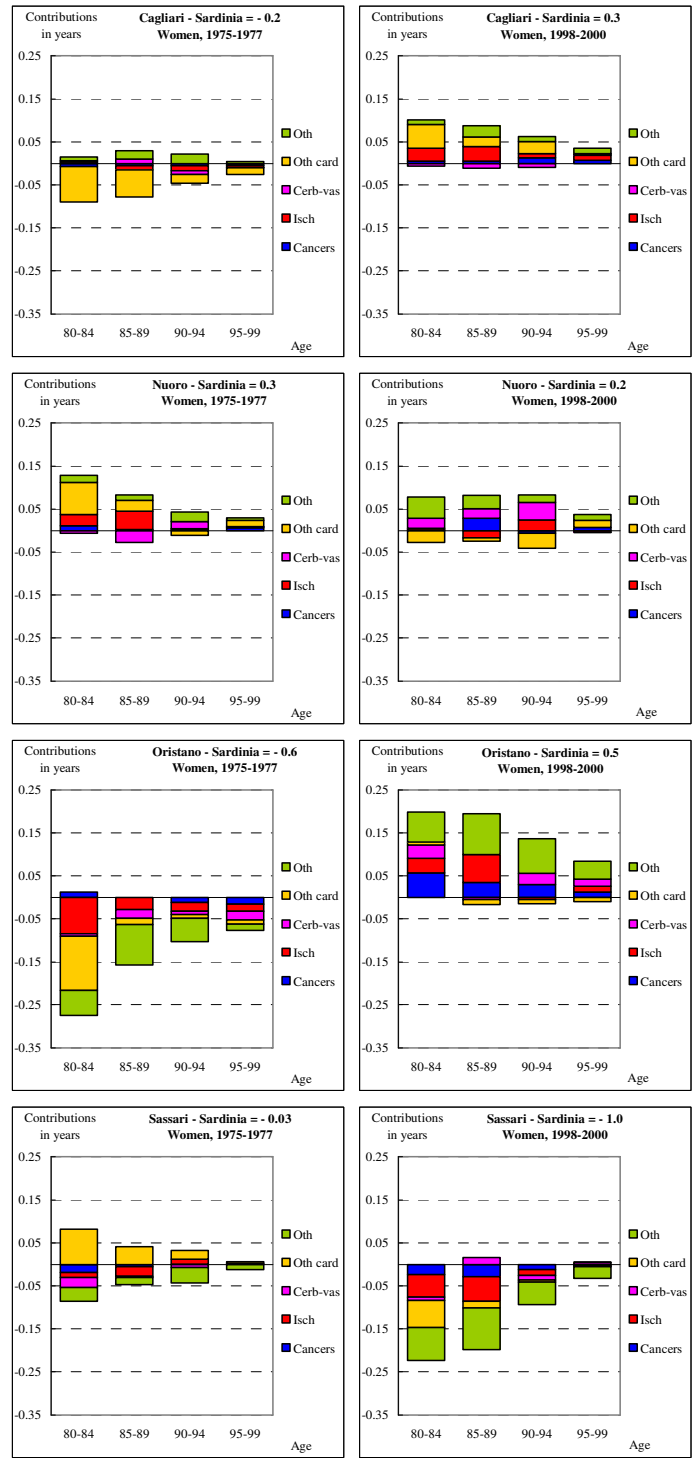
Figure 5: Contributions of mortality by various causes of death to differences in life expectancy at age 80 years between women and men.

Provinces. Years 1975-1977 and 1998-2000

(for differences in life expectancy see Table 2)
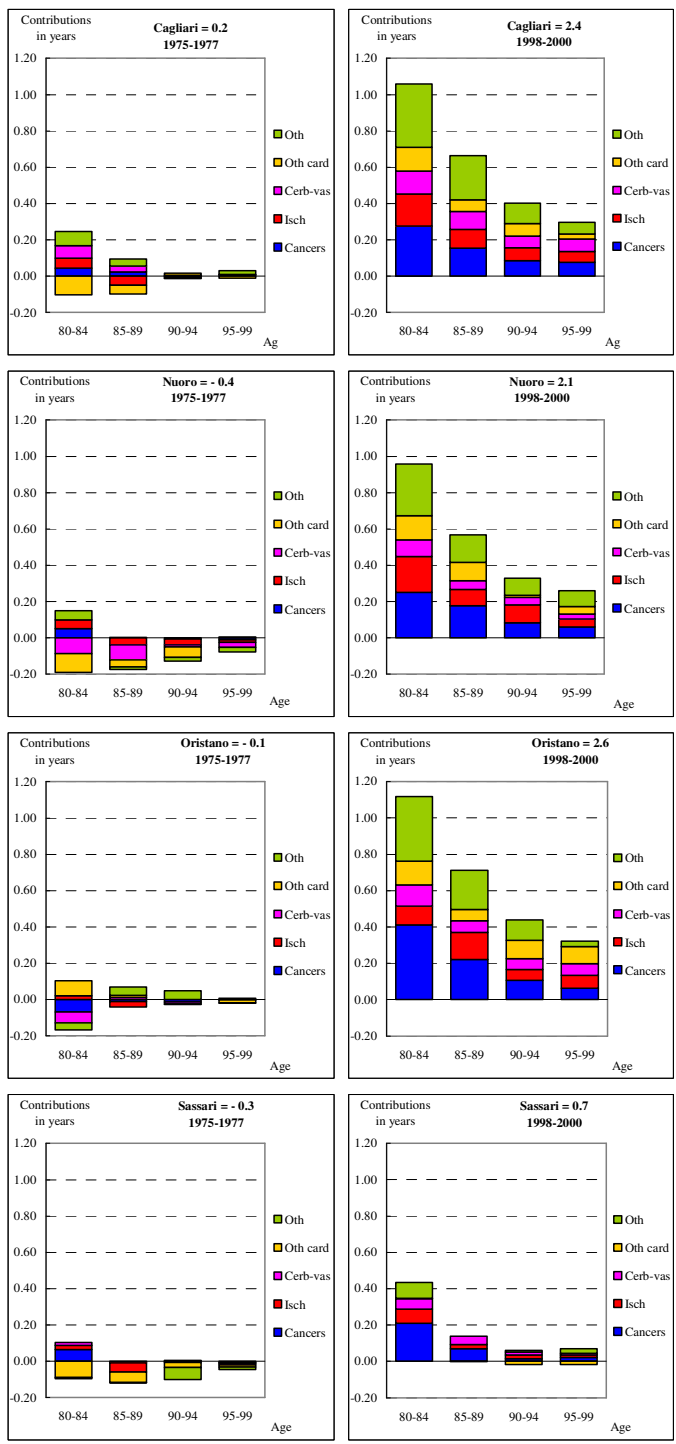


\section{Inter-municipality differences in mortality}

As each province comprises numerous municipalities each with different demographic features, its population heterogeneity can hinder explanatory analyses. Besides, by rigidly fixing boundaries there is a risk of overlooking geographic continuity in demographic behaviour. The adjacent provinces of Sassari and Nuoro are similar in terms of their male mortality at extreme ages; however, they could hide similarities in mortality across these provincial boundaries. Hence, what could be especially useful would be a spatial analysis of mortality after age 80 using a municipality indicator. However, as the population of the municipality is too small to ensure statistical significance, mortality probability or life expectancy cannot be used. Hence standardised mortality ratios are constructed by age group for various calendar years, thus guaranteeing a sufficient number of deaths in each group. Unfortunately, data are not available for the Sardinian municipalities for the entire period for each province. Data supplied by the Emilia-Romagna regional authorities only go up to 1994, however, provincial level analyses confirm that no substantial changes in the geography of mortality occurred in the 1990's.

As said in section 2, the indicator adopted for is the SMR for individual aged 80 and over. The SMR is a useful indicator for understanding underlying trends. This age group was selected rather than the 80-99 age group as centenarians have little or no impact on the overall municipal indicator due to the small number of deaths after this age. With the SMR for those aged 80 and over by sex, for each municipality, and for two periods, 1981-1989 and 1990-1994, and by applying the Kernel estimators as smoothing procedure (section 2), adjacent similar mortality zones could be identified.

\subsection{Geography of mortality: total and by causes of death}

Figures for both sexes allow for a comparison to be made between the municipality and province map of Sardinia and the all-cause and cause-specific mortality for the years 1981-1989 and 1990-1994. Low mortality is shaded in tones from blue to green, with higher mortality from orange to red. The geography of all-cause mortality highlights some interesting points (Figures 6 and 7). First, as was mentioned above similarities among the provinces may conceal different realities. For example, for men, (Figure 6), the areas comprising the municipalities of Sassari and Nuoro (with high life expectancy at age 80 ) during the second period show both high, low and very low mortality. Second, figures reveal trend changes in the geography of mortality. For example, the area of low male mortality in the north has shrunk, involving the more eastern municipalities of Sassari and others in Nuoro that are now comprised within the more 
disadvantaged zone. Similarly the situation has also worsened for women compared with the average (Figure 7) for the same municipalities in Nuoro and for those at the extreme north of Sassari. This may have generated the decline in the survival gap over time between the provinces mentioned above (sections 3.2 and 3.3). Linked to this is the fact that the area with the lowest mortality, although it has changed somewhat, maintains a geographic gradient that is shared by low mortality municipalities along the East, the North and South of the island. This more or less applies to both men and women although lately, as was stated, a number of more disadvantaged areas in Nuoro and Sassari have appeared in the low mortality zones.

A comparison by sex shows that low mortality zones only partially overlap (i.e comparing figure 6 with 7). Substantial differences occur for the province of Cagliari with, on average, the lowest female and the highest male mortality. It is worth recalling that Cagliari has the lowest life expectancy for men aged 80 (sections 3.2 and 3.3). Almost all the municipalities adjacent to the province of Nuoro are excluded from the high mortality (low life expectancy) zone. Interestingly this shows that the low mortality zone presents geographic continuities that do not respect provincial administrative divisions.

To identify which causes of death are responsible, the geography of all-cause mortality can be compared with mortality from cardiovascular diseases. The geography for all the municipalities is similar to that for all-cause mortality, while considerable differences for men occur for the western municipalities of the province of Cagliari. These latter municipalities, with an average high all-cause mortality, are found within the low cardiovascular mortality zone (Figure 6 and 7). Figure 8 shows that the recent geography of mortality from ischaemic hearth diseases is similar to that for cardiovascular diseases: explaining at the same time that mortality for this cause of death influences high mortality in the municipalities around the Gulf of Cagliari. Figure 9 throws light on why there is high mortality in municipalities in the West. The reason is cancer. As was seen for the entire province, high mortality from cancer is the underlying cause of high all-cause mortality from age 80 in Cagliari. Mortality is particularly high in the municipalities of "Sulcis inglesiente", that suffers environmental risks due to the presence of high-polluting mines, and also in the more industrialised western area.

The Italian Ministry of the Environment has listed 328 polluted sites in the province of Cagliari, 159 in the province Sassari (to the extreme north-west in the area known as Porto Torres, and with high mortality from cancers and ischaemic hearth diseases), 98 in the province of Oristano including those where dismantling asbestos is carried out (around the gulf and with above average mortality particularly from cancers) and 126 in the province of Nuoro (well evidenced due to above average mortality from cancer and ischaemic diseases). Recently municipalities along the northern coast are to 
be found in the high mortality area for these causes, home to the island's if not Italy's most exclusive ports.

Generally speaking the geography of mortality for Sardinian municipalities for men largely confirms the north-south divide that emerged from the analysis of provincial mortality for ischaemic heart diseases. However, additional information is gleaned in that the southern municipalities of the provinces of Nuoro and Oristano are found alongside low mortality municipalities of the South of the island. Moreover, taking the north of the region, numerous interior municipalities in the provinces of Sassari and Nuoro are excluded from the high mortality area for this cause, and they have the lowest all-cause mortality and mortality from cancer.

For women the province of Sassari's disadvantaged position is largely due to mortality from ischaemic heart diseases and cancers, found among the industrialised municipalities in the North and in the town of Sassari, where most of the province's population is concentrated. Mortality from cancers for women as for men is highest in those areas considered polluted by the Environmental Ministry.

The only recent exceptions are the western municipalities in the province of Cagliari where the geography of mortality from cancers is different for both sexes: on average higher for men and lower for women. For the latter rates for Cagliari for ages 80 and over life expectancy is one of the highest on the island, while the opposite is true for men.

It goes without saying that this brief analysis can be extended to the various geographic situations that emerged, although that performed to date on the geography of the mortality in the Sardinian municipalities is sufficient to be able to draw a number of conclusions. 
Figure 6: Geography of total mortality and mortality by cardiovascular diseases for men aged 80 and over. 1981-1989 and 1990-1994

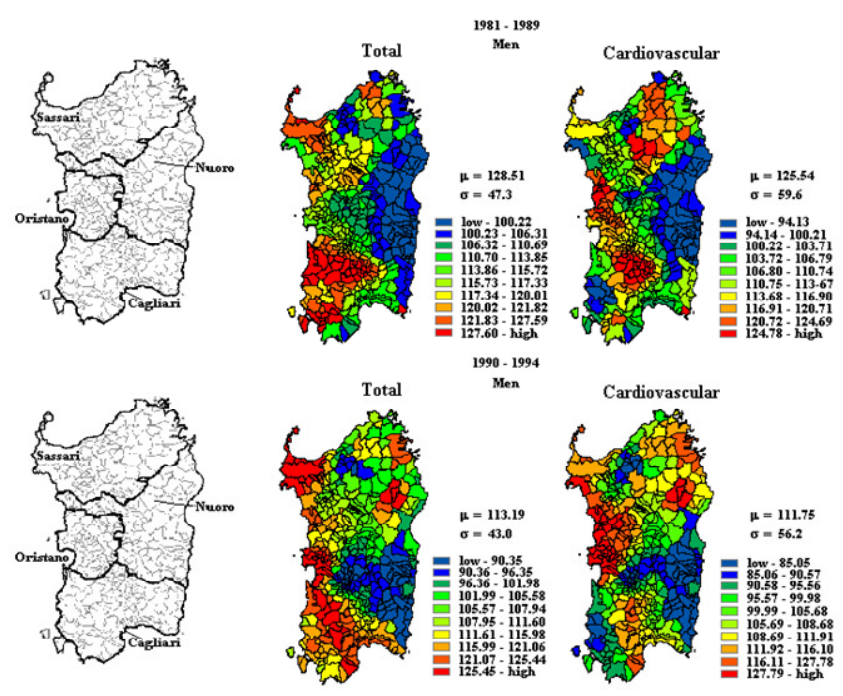

Figure 7: Geography of total mortality and mortality by cardiovascular diseases for women aged 80 and over. 1981-1989 and 1990-1994
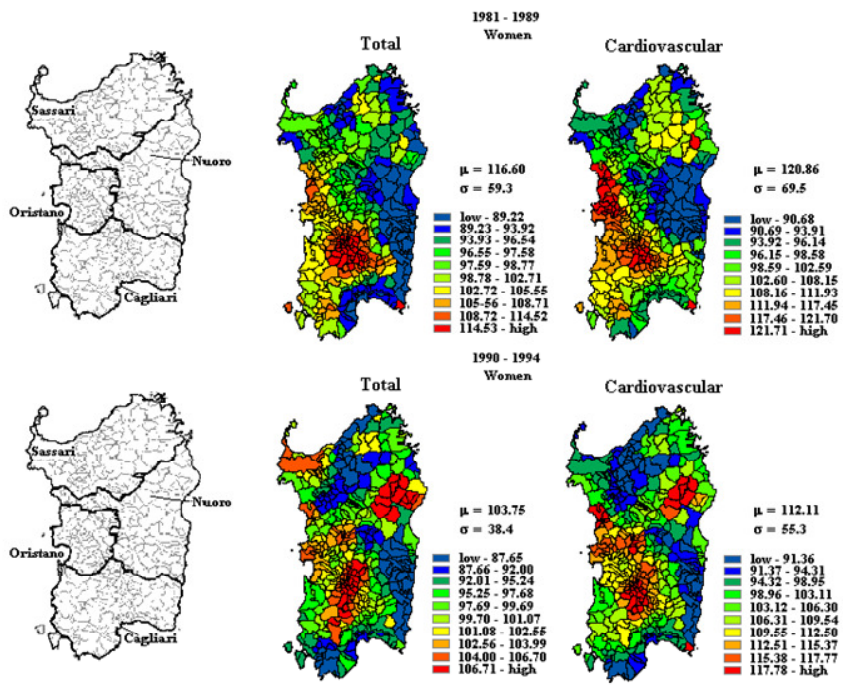
Figure 8: Geography of mortality by cardiovascular diseases and ischaemic heart diseases for men and women aged 80 and over. 1990-1994
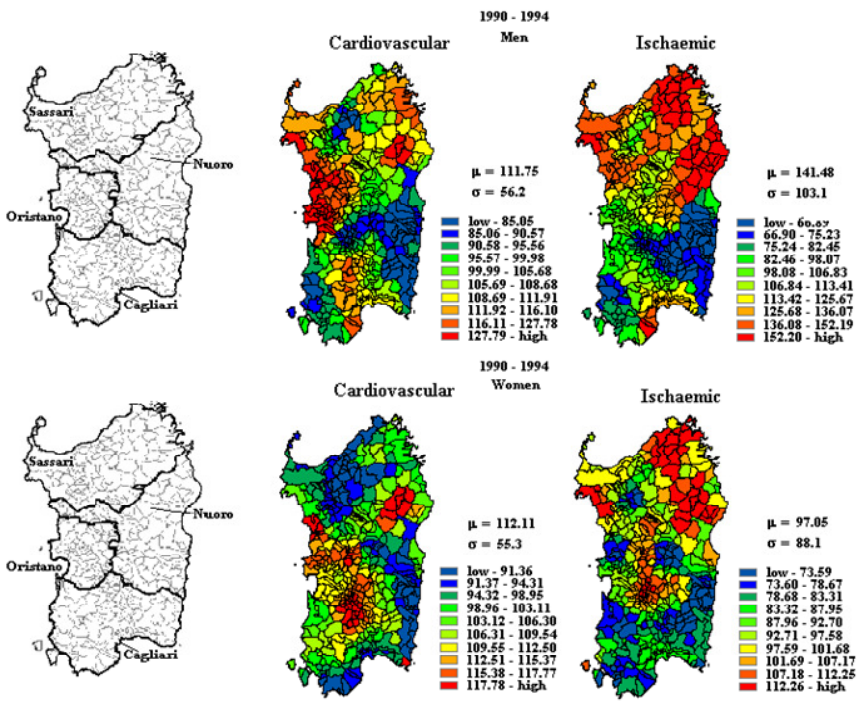

Figure 9: Geography of total mortality and mortality by cancers for men and women aged 80 and over. 1990-1994
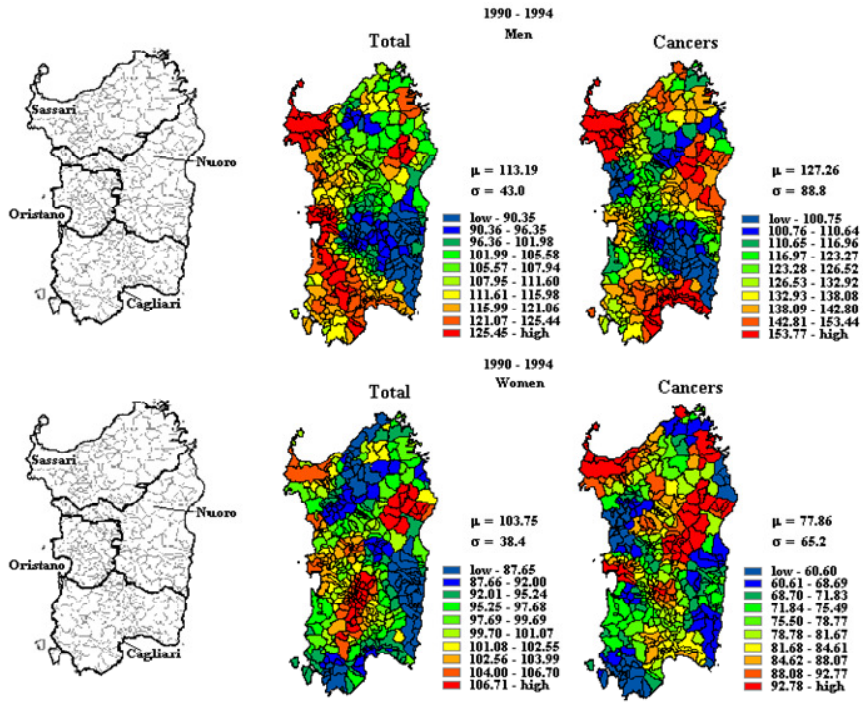


\section{Some answers}

As was tentatively stated in the introduction, the remarkable number of centenarians found in a given geographic area may be traced to low mortality after age 80. It could be expected that the geography of the two phenomena should coincide.

For the provinces, using 2001 census data on centenarians published by ISTAT (www.istat.it), Nuoro is the province with the highest number of centenarians as a total of the population (1.9 per 10000), followed by Oristano (1.4 per 10000; see Table 3 ). Of particular note is the much higher number of male centenarians in Nuoro than in other provinces, 1.2 compared to 0.4 for Cagliari, and almost double the regional average (0.7 per 10000). Moreover, from 1975-1977, Nuoro, has one of the highest 80year old male and female life expectancies and, thus, the lowest mortality after this age (see Table 2). Going by this analysis for this province, and focusing on men, the hypothesis that where there is over 80-year old low mortality the number of centenarians is also higher, would appear to be largely proved.

Table 3: The number of centenarians as a fraction of the whole population in Sardinia and in the provinces, by sex, at the 2001 census

\begin{tabular}{lrrrrrr}
\hline Municipalities & \multicolumn{1}{c}{ and region } & Number of centenarians & \multicolumn{4}{c}{$\begin{array}{c}\text { Proportion of centenarians in the } \\
\text { population (per 10000) }\end{array}$} \\
\cline { 2 - 7 } & Men & Women & Total & Men & Women & Total \\
\hline Cagliari & 15 & 49 & 64 & 0.4 & 1.3 & 0.8 \\
Nuoro & 16 & 33 & 49 & 1.2 & 2.5 & 1.9 \\
Oristano & 7 & 15 & 22 & 0.9 & 1.9 & 1.4 \\
Sassari & 15 & 37 & 52 & 0.7 & 1.6 & 1.1 \\
\hline Sardinia & 53 & 134 & 187 & 0.7 & 1.6 & 1.1 \\
\hline
\end{tabular}

However, the province is too much of a heterogeneous geographic entity to be representative of local situations that differ quite substantially. As was seen in section 4 what is true on average is no longer so when various geographic contexts are considered. Hence, accurate information can only be obtained when mortality and centenarians are considered within a municipal context.

At municipal level, a 2001 analysis on Sardinians born between 1880 and 1900 as part of the AKEA $1^{11}$ project (Poulain et al. 2004) showed that the area with the highest

${ }^{11}$ AKEA1 is the first project of the study on Sardinian centenarian, directed by Luca Deiana, Sassari University. The name "AKEA" is derived from an expression in the Sardinian dialect that means "may you live 100 years!" 
number of centenarians (indicated by Poulain et al. as the "Restricted Blue Zone") groups together inland, adjacent municipalities in the province of Nuoro (Figure 10). Here, for 1990-1994, male life expectancy at age 80 is 8.7 years compared with a regional average of 7.5 years, while that for women is 11.1 and 8.3 years ${ }^{12}$. This zone is part of a wider area (Extended Blue Zone) where the number of centenarians continues to outstrip the regional average and where life expectancy at age 80 for the same period is 8.2 for men and 8.7 years for women; once again topping the regional average. Inland municipalities in Oristano and Sassari fall within this zone, and they also enjoy the lowest over 80-year old mortality. Completely excluded from this zone are eastern municipalities in the province of Cagliari ${ }^{13}$ that, however, have a lower mortality. Another exception to the rule is a number of northern municipalities in Nuoro that have high mortality for all causes although found within the zone with the highest number of centenarians.

Aside from some exceptions it could largely be said that analogies between low mortality at ages 80 and over and the presence of centenarians is confirmed.

A further goal of this project was to ascertain the causes of death responsible for geographic differences in mortality. An in-depth analysis of cause-specific mortality differences and information on lifetime morbidity would be particularly useful. The results of these analyses could shed light on the factors that affect longevity in the population. For example, systemic chronic inflammation has been found to be related to mortality risks from different causes of death in older persons (Lio et al. 2003b 2004). Many studies discuss the critical importance of unregulated systemic inflammation in the shortening of survival in humans (Lio et al. 2003a). Sardinians, as we saw, are at an advantage to Italians enjoying lower cardiovascular mortality. In zones with the lowest mortality in Sardinia deaths from these diseases are lower than elsewhere. Besides offering an explanation for such differences, these findings indicate the existence of a specific genetic or environmental factor that protect Sardinian men. Further research is needed to clarify the exact nature of these factors.

At municipality level individual contexts are more complex with regard to mortality by cause. Taking cancers, and to an extent ischaemic diseases, in the more industrialised and polluted areas, the population's health is continually under siege and mortality is higher for these causes. It goes without saying that over 80-year old life expectancy and the number of centenarians are also lower.

This research shows that besides having "good" genes a favourable environment is also essential for longevity. Equally crucial is the ability to preserve one's health from external "assaults" that can curtail an individual's potential life span.

\footnotetext{
${ }^{12}$ Table available from graziella.caselli@uniroma1.it

${ }^{13}$ Why Cagliari is excluded from the centenarian zone may depend on the fact that some centenarians were not fully documented during AKEA1, and researchers may have decided not to include them because of doubts about the numbers involved.
} 
Figure 10: Geography of centenarian distribution, born in Sardinia from 1880 to 1900 (AKEA longevity), and of total mortality for men and women aged 80 plus in $1990-1994$

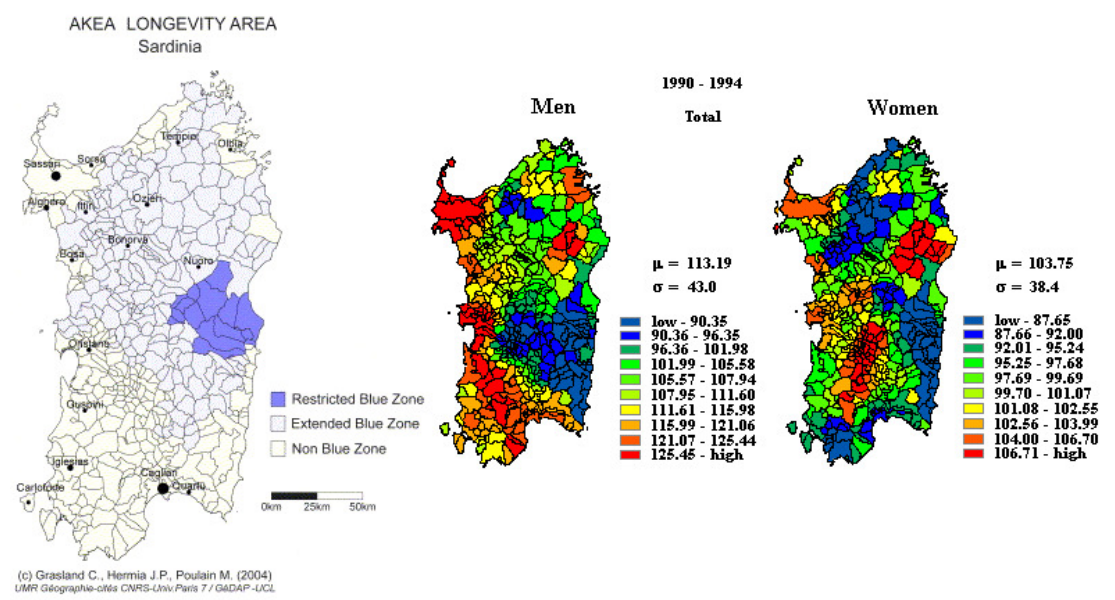

\section{Acknowledgements}

The authors wish to thank Karen Glaser and Cecilia Tomassini for their assistance with translation and James W. Vaupel for his careful revision of the paper. 


\section{References}

Biggeri A. and M. Marchi (1993) "Metodi di analisi spazio-temporale in campo epidemiologico: una rassegna". In ZANI Sergio (a cura di). Metodi statistici per le analisi territoriali. Milan, Franco Angeli, pp. 323-360.

Camnasio M., C. Cislaghi, R. Ferrari, G. Luppi and C. Montalbetti (1996) "Atlante epidemiologico geografico portatile ad utilizzo flessibile", Bollettino del CILEA, $\mathrm{n}^{\circ}$ 51, CILEA, Segrate (MI).

Capocaccia R. and G. Caselli (1990) "Popolazione residente per età e sesso nelle province italiane. Anni 1972-1981", Università degli studi di Roma "La Sapienza", Dipartimento di Scienze Demografiche, Fonti e strumenti, $\mathrm{n}^{\circ} 2$, Rome, pp.251.

Caselli G. and V. Egidi (1980) "Le differenze territoriali di mortalità in Italia. Tavole di mortalità provinciali (1971-72)", Istituto di Demografia dell'Università "La Sapienza" di Roma, n. 32, pp. 167.

Caselli G. and D. Rasulo (2005) "Centenarians in Sardinia: the underlying causes of low sex ratio", paper presented at XXV IUSSP Conference, Session 149 on "Mathematical and Formal Demography", Tours, 18-23 July 2005.

Caselli G., E. Barbi, C. Tomassini, S. Francisci, R.M. Lipsi, D. Pierannunzio (2002) "Analysis of Sardinian Mortality", Final Report, Max Planck Istitute, Rostock, May, 15.

Caselli G., J.M. Robine and D. Rasulo (2003) "Variations regionales du rapport de féminité en Italie". In Vallin J. (ed). Du genere et de l'Afrique, Omage à Thérèse Lococh, INED, Paris.

Cislaghi, C. (1998) “Atlante Italiano di Mortalità 1981-1994”, software versione 6.1, Regione Emilia Romagna, Ibsum, Cilea.

Golini A., L. Ciucci and G. Caselli, Istat (eds) (1983) "Ricostruzione della popolazione residente per sesso, età e regione. Anni 1952-1972”, Università degli Studi di Rome "La Sapienza", Dipartimento di Scienze Demografiche, Fonti e strumenti, $\mathrm{n}^{\circ} 1$, Rome, pp.365.

Istat (1974) "11 Censimento generale della popolazione - 24 ottobre 1971", Rome, Istituto Nazionale di Statistica. 
Istat (1976) "Tavole di mortalità della popolazione italiana per regione, 1970-72”. In Supplemento al Bollettino mensile di statistica n. 6, Rome, Istituto Nazionale di Statistica, pp.23.

Istat (1984) "Classificazione delle malattie, traumatismi e cause di morte, IX Revisione - 1975”, Metodi e Norme, vol. I, Serie C, n.10, Rome, Istituto Nazionale di Statistica, pp. 456.

Istat (1985) " $12^{\circ}$ Censimento generale della popolazione - 21 ottobre 1981", Rome, Istituto Nazionale di Statistica.

Istat (1987) "Tavole di mortalità della popolazione italiana per regione, 1979-83". In Note e Relazioni n. 1, Rome, Istituto Nazionale di Statistica, pp.58.

Istat (1995) " $13^{\circ}$ Censimento generale della popolazione e delle abitazioni - 20 ottobre 1991”, Rome, Istituto Nazionale di Statistica.

Istat (1996) "Ricostruzione della popolazione residente per età e sesso nelle province italiane. Anni 1982-1991”, Rome, Istituto Nazionale di Statistica, pp 414.

Istat (2000a) "Ricostruzione della popolazione residente, per sesso ed età nei comuni italiani. Anni 1982-1991”, Collana Informazioni, n 33, Cd rom allegato, Rome.

Istat (2000b) “Tavole provinciali di mortalità. Anno 1995”, Informazioni n. 12, Rome, Istituto Nazionale di Statistica, pp.212.

Istat (2004a) " $14^{\circ}$ Censimento generale della popolazione e delle abitazioni - 21 ottobre 2001", Sito web dell' Istituto Nazionale di Statistica: www.istat.it, Rome.

Istat (2004b) "Tavole di mortalità della popolazione italiana per provincia, 2000", Sito web dell'Istituto Nazionale di Statistica: www.istat.it, Rome.

Kahn H. A. and C. T. Sempos (1989) "Statistical Methods in Epidemiology", New York, Oxford University Press, pp.292.

Kannisto, V. (1994) "Development of Oldest-old Mortality, 1950-1990: Evidence from 28 Developed Countries", Odense Monographs on Population Aging, $\mathrm{n}^{\circ} 1$, Odense University Press, Odense (Denmark).

Kannisto V., J. Lauritsen, A. R. Thatcher and J. Vaupel (1994) "Reductions in Mortality at Advanced Ages: Several Decades of Evidence from 27 Countries", in Population and Development Review 20(4): 793-810.

Lio D., G. Candore, A. Crivello, L. Scola, G. Colonna-Romano, L. Cavallone, E. Hoffman, M. Caruso, F. Licastro, C.M. Caldarera, A. Branzi, C. Franceschi and 
C. Caruso (2004) "Opposite effects of interleukin 10 common gene polymorphisms in cardiovascular diseases and in successful ageing: genetic background of male centenarians in protective against coronary heart disease", Journal of Medical Genetics 41 (10): 290-794.

Lio D., G.M. Pes, C. Carru, F. Listi, V. Ferlazzo, G. Candore, G. Colonna-Romano, L. Ferrucci, L. Deiana, G. Baggio, C. Franceschi and C. Caruso (2003a) "Association between the HLA-DR alleles and longevity: a study in Sardinian population", Experimental Gerontology 38 (Issue 3).

Lio D., L. Scola, A. Crivello, G. Colonna-Romano, G. Candore, M. Bonafé, L. Cavallone, F. Marchigiani, F. Olivieri, C. Franceschi and C. Caruso (2003b) "Inflammation, genetics, and longevity: further studies on the protective effects in men of IL-10 -1082 promoter SNP and its interaction with TNF- $\boldsymbol{\alpha}-308$ promoter SNP", Journal of Medical Genetics 40.

Lipsi R. M. and G. Caselli (2002) "Evoluzione della geografia della mortalità in Italia Tavole provinciali e probabilità di morte per causa - Anni: 1971-1973, 19811983, 1991-1993", Vol.4, Collana: Fonti e Strumenti, Rome, Dipartimento di Scienze Demografiche, pp. 244.

Pollard, J.H. (1986) "Cause of death and expectation of life: some international comparisons". Seminar on Comparative studies of mortality and morbidty: old and new approaches to measurement and analysis, Siena, IUSSP, pp.38.

Poulain M., G.M. Pes, C. Grasland, C. Carru, L. Ferrucci, G. Baggio, C. Franceschi and L. Deiana (2004) "Identification of a geographic area characterized by estreme longevity in the Sardinia island: the AKEA study", Experimental Gerontology 39: 1423-1429.

Robine, J.M, and G. Caselli (2005) "An unprecedented increase in the number of centenarians" Genus LXI (1): 57-82.

Silverman B.W. (1986) "Density Estimation for Statistics and Data Analysis". In Monographs on statistics and applied probability, London, Chapman and Hall.

Thatcher A. Roger, Kannisto Väino, Vaupel James W. (1998), The Force of Mortality at Ages 80 to 120, Odense Monographs on Population Aging, $\mathrm{n}^{\circ} 5$, Odense University Press, Odense (Danimarca).

Thatcher, R. A. (2001) "The Demography of Centenarians in England and Wales" Population - An English Selection, INED 13(1): 1-139. 
Vaupel, J.W. and B. Jeune (1995) "The emergence and proliferation of centenarians". In B. Jeune and J.W. Vaupel (eds). Exceptional longevity: from prehistory to the present, Monographs on Population Aging No. 2. Odense, Denmark, Odense University Press, pp.109-116. 
Caselli \& Lipsi: Survival differences among the oldest old in Sardinia 